\title{
ANÁliSe DAS AÇões DEFENSIVAS E OFENSIVAS, E PERFIL METABóliCO DA ATIVIDADE DO GOLEIRO DE FUTEBOL PROFISSIONAL
}

Carlos Roberto Gallo

Carlos Aparecido Zamai

Laércio Vendite

Cleyton Libardi

\section{Resumo}

O objetivo deste estudo foi analisar a atividade do goleiro, durante 12 jogos, para obter um perfil metabólico da sua atividade e uma direção de treinamento mais adequada às reais necessidades da posição. A metodologia utilizada consistiu inicialmente de levantamento bibliográfico sobre o goleiro e suas funções, além das características morfológicas, tipos de fibras musculares, metabolismo energético e ações motoras praticadas durante o jogo . Também foi realizada pesquisa de campo com coleta de dados quantificando as ações motoras, pré-estabelecidas, nos momentos em que aconteceram. Foram registradas em uma planilha específica que permite visualizar os momentos ativos e sem intervenções no jogo. Os resultados obtidos foram os seguintes: 93 ações de saltos/quedas/defesas, 95 saídas do gol (cruzamentos, enfrentamentos, antecipações), e 267 reposições de bola (passes, lançamentos) totalizando 455 ações motoras praticadas em 12 jogos. A média obtida por jogo foi de: 7,8 saltos/quedas/defesas, 7,9 saídas do gol, e 22,3 reposições em 37,9 ações gerais praticadas. Por intermédio dos resultados, conclui-se que a atividade de alta intensidade (defesas,saídas do gol ou lançamentos) é de curtíssima duração e o tempo entre uma e outra é longo e suficiente para recuperação. Portanto o perfil de taxa de trabalho do goleiro implica mais na potência anaeróbica alática, resultando numa pequena depleção de ATP-CP, do que qualquer outra demanda no sistema de transporte de oxigênio.

\section{Palavras-Chaves}

Goleiro; Caracterização; Metabolismo; Treinamento específico.

\section{ANALYSIS OF THE DEFENSIVE AND OFFENSIVE ACTIONS, AND METABOLIC PROFILE OF THE ACTIVITY OF THE PROFESSIONAL SOCCER GOALKEEPER}

Carlos Roberto Gallo

Carlos Aparecido Zamai

Laércio Vendite

Cleyton Libardi

\begin{abstract}
This research intends to analyze the goalkeeper activity while 12 soccer matches to obtain a metabolic profile of his activity and a better methodology of coaching the goalkeeper real necessities. The methodology used in this research consisted in analyses of readings about the functions, morphological characteristics, kinds of muscular fibers, energetic metabolism, specific movements and coaching of the goalkeeper. It was made a field research to quantify the goalkeeper movements and when they happened. The information was registered in a specific worksheet which shows the active and without intervention movements of the goalkeeper while a match. The results were: 93 jumps/declines/defenses, 95 goal exits (intersections, facing, advances) and 267 balls replacement (pass, releases) totaling 455 movements in 12 matches. The average obtained for match was: 7, 8 jumps/declines/defenses, 7, 9 goal exits and 22, 3 balls replacement in 37,9 movements. After the information analysis it was concluded that the high intensity activity (defenses, goal exits or pass) has a short time duration and the period of time between them is long and sufficient to the recovery (an action is performed about every 2 minutes and 40


seconds). Thus the goalkeeper work involves more anaerobic non-creamery power, resulting in a little depletion of ATP-CP, than any other demand in the oxygen system of transport.

\section{Key-Words}

Goalkeeper; Characterization; Metabolism; Specific coaching. 


\section{INTRODUÇ̃̃O}

\section{O goleiro e suas funções}

Dos onze jogadores que compõem a equipe, Maier (1981) destaca a responsabilidade e a importância vital do goleiro, sendo que sua participação poderá implicar diretamente no resultado do jogo. Para Csanádi (1987), um bom goleiro ajuda muito a sua equipe que poderá vencer outra mais forte, ao contrário, se não for bom poderá prejudicar uma equipe grandiosa.

São poucos os jogadores que possuem a quantidade de capacidades corporais e psíquicas exigidas do goleiro como afirma Carlesso (1981). É um atleta que precisa ter formação corporal excepcional, segundo Freire (1998), pois tem a possibilidade de utilizar qualquer parte do corpo no contato com a bola.

Carlesso (1981) destaca o goleiro como um elemento da equipe com múltiplas funções, e entre elas estão: a defesa da meta, a reposição da bola em jogo e a orientação do jogo. A base principal de seu jogo, segundo Voser et al (2006), é impedir que sua equipe não sofra gols. Sendo assim, alguns fundamentos técnicos que o goleiro deve dominar para desempenhar bem sua função defensiva são destacados por Domingues (1997), como: pegada alta no meio, pegada na altura do peito, encaixe, defesa rasteira no meio, defesa rasteira nas laterais, defesa à meia altura nas laterais, defesa alta no meio, defesa alta nas laterais, defesa com os pés, saídas nos cruzamentos, enfrentamento, penalidade máxima e defesas com formação de barreiras.

Os fundamentos técnicos para serem executados sob uma condição favorável requerem uma preparação física condizente. Kraemer e Häkkinen (2004, p.89) afirmam que para defender a bola o goleiro necessita de "um alto grau de velocidade de reação, agilidade em direções diferentes a partir de diversas posições do corpo, velocidade para levantar do solo e capacidade de mergulho e lançamento do corpo em outra direção, altura de salto e velocidade inicial em um tiro para frente ou para trás".

Outra função importante é a reposição de bola. Com as evoluções táticas há necessidade de se organizar jogadas desde a saída de bola do goleiro por intermédio de passes precisos. Segundo Frisselli e Mantovani (1999), o goleiro pode ser o primeiro jogador a reiniciar o jogo, assim como aquele que inicia o contra-ataque. A reposição da bola poderá ser feita com as mãos ou com os pés, de acordo com a distância e habilidade do membro a utilizar. 


\section{CARACTERÍSTICAS MORFOLÓGICAS DO GOLEIRO}

Mc Ardle (2003) relaciona um alto nível de desempenho desportivo ao biótipo do atleta, no entanto, essas medidas apresentam grandes variações e, de acordo com essas dimensões corporais, o desempenho do futebolista poderá ser beneficiado ou prejudicado. As medidas de tamanho, massa corporal e composição corporal (massa magra, massa gorda e porcentual de gordura), de acordo com Prado et al (2006), devem estar adequadas para a especificidade da função que o atleta ocupa na equipe e são fundamentais.

Kraemer e Häkkinen (2004) constataram que os goleiros possuem uma tendência de serem mais altos e pesados que os demais elementos da equipe. Essa tendência ficou evidenciada em diversos outros estudos como o de Voser et al (2006), que se referem à estatura do goleiro entre 1,85 até 1,95 metros, como sendo a ideal. Teixeira et al (2006) relatam que no mundial de futebol realizado na Alemanha, no ano de 2006, estiveram presentes 96 goleiros de diversas seleções, sendo que a média de estatura foi de $1,88 \mathrm{~m}$ e a de massa corporal de $84,00 \mathrm{~kg}$. Bangsbo (1994) obteve média de $1,89 \mathrm{~m}$ para os goleiros do futebol dinamarquês.

Prado et al (2006) e Rocha Filho (2000) verificaram a tendência dos goleiros terem uma porcentagem de gordura e massa gorda mais elevadas que os jogadores das demais posições, que são justificadas pela menor sobrecarga metabólica nos jogos e treinamentos. Um percentual entre $9 \%$ até $12 \%$ foi sugerido por Voser et al (2006). Rocha Filho (2000) constatou que os goleiros também apresentam a maior média de massa magra que os outros futebolistas profissionais.

\section{FIBRAS MUSCULARES}

A principal função do músculo esquelético é a contração que resulta em movimento. É constituído por vários tipos de fibras musculares, sendo que a proporção desses tipos de fibras, nos grupos musculares, varia de um indivíduo para outro. Segundo Powers e Howley (2000), essa proporção é determinada geneticamente e pode ser influenciada pelos níveis hormonais no sangue e hábitos que o indivíduo tem de se exercitar. Elas são classificadas, basicamente, em três tipos, segundo Foss e Keteyan (2000): uma de contração lenta que é a tipo I, e dois subtipos de contração rápida, tipo Ila e tipo IIb, cujas características estão apresentadas no quadro 1. 


\begin{tabular}{|c|c|c|c|}
\hline Características & $\overline{\text { Tipo I }}$ & Tipo IIa & Tipo IIb \\
\hline Limiar de excitabilidade & - & + & ++ \\
\hline Conteúdo em fosfagênios & - & + & ++ \\
\hline Conteúdo em glicogênio & - & + & ++ \\
\hline Conteúdo em triglicerídeos & ++ & + & - \\
\hline Resistência à fadiga & ++ & + & - \\
\hline Eficiência energética & ++ & + & - \\
\hline Força de contração & - & + & ++ \\
\hline Contratilidade & Lentas & Rápidas & Muito rápidas \\
\hline
\end{tabular}

Quadro 1- Características básicas dos tipos de fibras musculares.

Fonte: Soares (2005), p. 102.

Como se pode verificar no quadro 1, os três tipos de fibras possuem características bem definidas e diferenciadas. As do tipo I (fibras de contração lenta) são muito resistentes à fadiga, tem muita capacidade de metabolismo aeróbico. O predomínio no recrutamento de fibras tipo IIb é típico de atividades anaeróbicas aláticas (intensidade alta e curtíssima duração). No tipo IIa as fibras apresentam um perfil metabólico misto com elevada atividade glicolítica (anaeróbica lática), assim como também oxidativa, sendo um tipo de fibra intermediária entre o tipo I e IIb (SOARES, 2005).

\section{METABOLISMO ENERGÉTICO}

O ATP (adenosina trifosfato) é a fonte imediata de energia para a contração muscular (FOSS e KETEYAN, 2000). Durante o exercício é exigido um suprimento constante de ATP para haver energia necessária à contração muscular, no entanto existe uma quantidade limitada de ATP na célula muscular que dura apenas de 2 a 3 segundos. O atleta tem que continuar a obter ATP, para realizar a atividade física, que se dará por intermédio de 3 processos metabólicos para reposição do fosfato da energia.

De acordo com Powers e Howley (2000), a regeneração do ATP ocorre por três processos produtores de energia que são: sistema ATP-CP, sistema glicolítico e sistema oxidativo. A utilização de um ou outro sistema implica na velocidade e no tempo que se pode liberar energia e fosfato para a reposição do ATP, embora todos os processos metabólicos liberem energia, quase que simultaneamente, após o início do exercício, segundo La Rosa (2004).

No início do exercício e na produção de ações fortes, rápidas e de curta duração a energia utilizada na contração muscular se origina da reação ATP-CP. É o método mais simples e rápido na produção de ATP e tem disponibilidade imediata para o músculo. A regeneração pela CP é feita com tal rapidez que a velocidade nos exercícios não diminui, porém, como a quantidade total de energia pela CP é pequena, Conexões: revista da Faculdade de Educação Física da UNICAMP, Campinas, v. 8, n. 1, p. 16-37, jan./abr. 2010. 
ocorre depleção e limita o trabalho. A CP armazenada nos músculos só é suficiente para ser utilizada em 5 a 10 segundos, no entanto sua restauração, de acordo com vários estudos, ocorre muito rapidamente e $70 \%$ dos fosfagênios são restabelecidos em 30 segundos. O sistema dos fosfagênios (ATP-CP) é fundamental para as atividades que exigem um fornecimento rápido de energia ATP e não uma grande quantidade (FOSS; KETEYAN, 2000).

Após um período de esforço máximo o suprimento de creatina fosfato se esgota e a energia para a regeneração contínua da ATP, segundo Mc Ardle et al., (2003), terá como principal fonte o processo glicolítico que é mais lento. É uma segunda via metabólica que proporciona fornecimento de ATP relativamente rápido. Nos esforços de intensidade máxima, com duração entre 20 segundos e 5 minutos, a maior parte das necessidades energéticas provém dos estoques de glicogênio muscular para a produção de energia anaeróbica (MAUGHAN et al., 2000). A fonte de energia produzida pela glicólise anaeróbica possui um pouco mais de capacidade que o sistema ATP-CP, porém com um pouco menos de potência (FLECK; KRAEMER, 2002).

O sistema oxidativo é uma terceira via metabólica, com menor ritmo de demanda de energia ATP e com uso de oxigênio. Foss e Keteyan (2000) descrevem o sistema aeróbico como um sistema muito mais complexo que os outros dois que não fazem uso de oxigênio. A fosforilação oxidativa é a menos poderosa quando comparada com as fontes de energia anaeróbica, afirmam Fleck e kraemer (2002). No entanto, é a fonte predominante de energia para atividades de longa duração e baixa intensidade. Embora não possa produzir uma quantidade de ATP, por segundo, suficiente para executar exercício de intensidade máxima, por outro lado, a via aeróbica pode fornecer uma quantidade ilimitada de ATP num período longo de tempo.

\section{CARACTERÍSTICA DA ATIVIDADE DOS FUTEBOLISTAS DURANTE O JOGO.}

De acordo com Barbanti (2002) e Weineck (2000), as dimensões do campo de futebol são relativamente grandes e, durante um jogo com duração de 90 minutos, os jogadores de ambas as equipes praticam cerca de mil diferentes ações nas situações específicas de defesa e ataque. Há mudanças rápidas de ritmos e direção, saltos, arranques, corridas, paradas bruscas e execução das habilidades do jogo.

As exigências físicas no futebol podem ser avaliadas a partir da análise (movimento/tempo) dos tipos de ações dos jogadores durante o jogo, segundo Bangsbo (2008) e Seluianov et al (2008). 
$\overline{\text { Em relação às ações técnico-táticas individuais (habilidades do jogo), Gomes e Souza (2008) apresentam }}$ resultados de pesquisas em que, um dos jogadores analisados obteve média de 34,6 ações e outro de 47,6. No entanto, um terceiro jogador praticou em um único jogo 112 ações. Para a análise dos fundamentos técnicos, feita com o goleiro, Domingues (1997) obteve a média de 30,36 ações em 143 jogos. Dados que levam à conclusão de que, tanto a função exercida pelo atleta como as circunstâncias de cada jogo são importantes para determinar a variedade dos volumes das ações.

Com a finalidade de medir a extensão e a intensidade que os jogadores se movimentam durante o jogo, outros estudos foram realizados. Em um deles, Bangsbo (2008) verificou a distância média percorrida de 10,6 km, obtidas no futebol dinamarquês, com oscilações entre 9 e 14 km. Frisselli e Mantovani (1999) apresentaram dados coletados pela equipe técnica do São Paulo F.C., nos quais o resultado médio foi de 7.488 metros percorridos, variando entre 6.610 metros e 8.514 metros. Weineck (2000) afirma sobre variações entre 9 e $12 \mathrm{~km}$, sendo que houveram desempenhos de até $14 \mathrm{~km}$.

Para os goleiros, no entanto, os números obtidos na análise dos percursos são muito inferiores aos obtidos pelos futebolistas das outras posições. Bangsbo (2008) e Barbanti (2002) relataram que os goleiros percorreram, em média, cerca de $4 \mathrm{~km}$ durante o jogo, que podem ser explicados pelo fato de estarem constantemente se movimentando para manter o aquecimento, e não pela necessidade de intervir especificamente de acordo com suas funções. No quadro 2 são apresentados os percursos médios, comparativos, entre goleiros e demais futebolistas profissionais.

\begin{tabular}{|c|c|c|c|c|c|c|}
\hline & Total & Andando & Trotando & $\begin{array}{l}\text { Velocidade } \\
\text { Sub. Máx. }\end{array}$ & $\begin{array}{l}\text { Velocidade } \\
\text { Máxima }\end{array}$ & $\begin{array}{c}\text { Movimento } \\
\text { Para trás }\end{array}$ \\
\hline & 3.9 & & 1.0 & 496 & $32 \mathrm{~m}$ & $1.018 \mathrm{~m}$ \\
\hline Jog & $8.680 \mathrm{~m}$ & $2.150 \mathrm{~m}$ & $3.187 \mathrm{~m}$ & $1.810 \mathrm{~m}$ & $974 \mathrm{~m}$ & $559 \mathrm{~m}$ \\
\hline
\end{tabular}

Quadro 2- Distâncias médias percorridas pelo goleiro e jogadores.

Fonte: Barbanti (2002, p.93-95).

Ao comparar valores de limiar anaeróbico e consumo máximo de oxigênio em jogadores de futebol de diferentes posições, Balikian et al (2002) obtiveram resultados que foram inferiores para o grupo de goleiros em relação aos demais grupos (outras posições). Sant'anna e Ávila (2006) estabeleceram o padrão de $\mathrm{VO}_{2}$ máximo, em atletas de futebol, em torno de 55 a $65 \mathrm{ml} / \mathrm{kg} / \mathrm{min}$. Balikian et al (2002) obtiveram para os goleiros, $\mathrm{VO}_{2}$ máximo com média de 52,68 $\mathrm{ml} / \mathrm{kg} / \mathrm{min}$. Com base nesses dados, pode- 
se concluir que, nessa comparação, os menores valores de capacidade aeróbica apresentados pelos goleiros é devido à menor solicitação do sistema aeróbico durante o jogo. Mais de $85 \%$ da área percorrida é realizada em intensidade muito baixa.

Por outro lado, Frisselli e Mantovani (1999), na avaliação das impulsões horizontal e vertical, e índice de potência, encontraram resultados superiores apresentados pelos goleiros profissionais sobre os futebolistas das outras posições, conforme apresentado no quadro 3.

\begin{tabular}{|c|c|c|c|c|c|c|}
\hline & Goleiros & Laterais & Zagueiros & Volantes & Meias & Atacantes \\
\hline $\begin{array}{l}\text { Impulsão } \\
\text { Horizontal }\end{array}$ & $249 \mathrm{~cm}$ & $243 \mathrm{~cm}$ & $230 \mathrm{~cm}$ & $221 \mathrm{~cm}$ & $242 \mathrm{~cm}$ & $235 \mathrm{~cm}$ \\
\hline $\begin{array}{l}\text { Impulsão } \\
\text { Vertical }\end{array}$ & $65,5 \mathrm{~cm}$ & $56,5 \mathrm{~cm}$ & $55 \mathrm{~cm}$ & $45 \mathrm{~cm}$ & $55 \mathrm{~cm}$ & $62 \mathrm{~cm}$ \\
\hline $\begin{array}{l}\text { Índice de } \\
\text { Potência }\end{array}$ & 260,3 & 243,1 & 238,2 & 224 & 220,1 & 224,9 \\
\hline
\end{tabular}

Quadro 3- Avaliação comparativa entre futebolistas.

Fonte: Frisselli e Mantovani (1999, p.209).

Desta forma, os resultados obtidos de diferentes estudos sugerem que, tanto para a posição como para a função exercida pelo futebolista, há um nível de solicitação diferenciado, o qual exigirá e desenvolverá adaptações nos processos envolvidos na atividade. Os goleiros possuem características totalmente diferenciadas dos demais futebolistas, conforme os quadros 2 e 3, que demonstra adaptação específica para sua atividade.

\section{CONSIDERAÇÕES SOBRE AS CARACTERÍSTICAS ATUAIS DO TREINAMENTO DE GOLEIROS}

Houve grandes avanços nas pesquisas referentes às áreas de físiologia do exercício, medicina e psicologia esportiva. No entanto, no que se refere à especificidade do treinamento de goleiros há falta de trabalhos relacionados às necessidades energéticas do jogo, bem como do perfil da preparação física da posição deste profissional.

Uma afirmação muito importante é feita por Aoki (2000), referindo-se aos goleiros das seleções campeãs mundiais, na qual o goleiro brasileiro era o que apresentava menor capacidade competitiva. O motivo sugerido é devido ao mesmo tratamento dado a todos os jogadores, nos treinamentos, não considerando a especificidade da posição do goleiro. Na seleção brasileira, campeã mundial de 1994, Gomes et al (1996) constataram que o grupo de jogadores apresentavam potência aeróbia homogênea, inclusive os goleiros. 
O método mais comum aplicado ao treinamento do goleiro, geralmente, provém de uma herança prática que os treinadores (na maioria ex-goleiros) adquiriram na época que atuavam como goleiros profissionais. Segundo Lopes (2001), muitas vezes os goleiros são submetidos a exercícios com intensidade elevada e duração bem superior (em torno de 20 a 30 segundos cada exercício) às ações específicas praticadas por ele no jogo, que irão provocar uma grande estimulação do metabolismo anaeróbico lático. Essa é uma característica predominante nos futebolistas de outras posições, de acordo com Bangsbo (2008). Ao contrário, o goleiro realiza exclusivamente ações de curta duração e alta intensidade, que dependem predominantemente do sistema anaeróbico alático (BALIKIAN et al., 2002).

Por isto, é importante avaliar as exigências físicas do futebol a partir da análise (movimento/tempo) dos tipos de ações dos jogadores durante o jogo (BANGSBO, 2008; SELUIANOV et al., 2008). Quando os movimentos são intensos e curtos (de 5 a 10 segundos) há predomínio no recrutamento de fibras musculares tipo IIb, com utilização da energia anaeróbica alática (ATP-CP). Após esse curto período, com a continuidade do movimento, esgotam-se as reservas de $\mathrm{CP}$ e as fibras Ilb entram em falência funcional, de acordo com Soares (2005), e começa haver predomínio no recrutamento de fibras tipo IIa, que são menos potentes e se beneficiam da energia proveniente do metabolismo anaeróbico lático.

Estas relações são determinantes quando se trata da preparação de atletas de alto rendimento. No caso do treinamento de goleiro, que implica muito mais em potência muscular, segundo Barbanti (2002), se o exercício com intensidade elevada for prolongado deixa de atender esta capacidade física (potência) para beneficiar a de resistência, que não é tão relevante na sua atividade de jogo (SOARES, 2005).

Com preocupação neste sentido, Voser et al (2006) afirmam a importância da pesquisa, da investigação, da discussão e apresentação de resultados científicos na área de atuação do goleiro de futebol para se elaborar treinamentos técnico, físico, tático e psicológico associados, mais próximos da realidade dos jogos.

\section{OBJETIVO}

O objetivo deste estudo foi analisar as ações motoras praticadas pelo goleiro, durante vários jogos de futebol profissional, para obter o perfil metabólico das atividades praticadas e para elaboração de um modelo de treinamento coerente às reais exigências e especificidades da função. 


\section{METODOLOGIA}

Para a realização deste estudo observou-se a atuação do goleiro profissional, pertencente a um clube de futebol localizado no interior do Estado de São Paulo. A pesquisa foi feita durante 12 jogos de uma competição oficial nacional, no ano de 2008. Das 12 partidas analisadas, 6 delas ocorreram em seu próprio estádio, com mando de jogo, e 6 partidas no campo dos adversários. Todos os jogos foram no decorrer do primeiro turno da competição, da $8^{\mathrm{a}}$ rodada até a $19^{\mathrm{a}}$ rodada (último jogo do turno). $\mathrm{Na}$ execução dos procedimentos para a coleta de dados e tabulação dos mesmos, foram utilizados: DVDs com as gravações dos jogos e planilhas específicas (desenvolvidas com o propósito de armazenamento dos registros). As ações motoras estabelecidas para registro foram:

- Salto/queda/defesa: são ações do jogo, específicas à função do goleiro, em que o mesmo faz o movimento completo para tentar defender a bola, independente de ter êxito ou não;

- Saída do gol: ações em que o goleiro abandona sua meta para interceptar a bola;

- Reposição (passes e lançamentos): ato de repor a bola, direcionada a um companheiro, que podem ser efetuadas com as mãos ou pés.

Os registros das ações motoras de saltos/quedas/defesas, saídas do gol e reposições de bola foram anotadas na forma de legenda, no tempo de jogo que as mesmas ocorreram, observando-se a gravação do jogo (DVD). Todas as ações caracterizadas, praticadas no jogo, foram registradas numa única planilha específica, em períodos de 15 minutos, na qual poderão ser observados todos os momentos de intervenções do goleiro e o tempo sem atividades entre as ações. Decidiu-se por estes procedimentos por serem a forma mais adequada a este estudo, permitindo uma análise mais equilibrada das práticas. $\mathrm{O}$ modelo da planilha utilizada é mostrado a seguir. 
Planilha de coleta de dados (seqüência de ações motoras)

Jogo:

Data:

Local:

Horário:

\section{$1^{\circ}$ TEMPO}

\begin{tabular}{|c|c|c|c|c|c|c|c|c|c|c|c|c|c|c|c|c|}
\hline & 0' & $\mathbf{1}^{\prime}$ & 2' & 3' & $4^{\prime}$ & 5 & $6{ }^{\prime}$ & 7 & 8 & 9' & $10^{\prime}$ & $11^{\prime}$ & $12^{\prime}$ & 13' & 14 & $15^{\prime}$ \\
\hline $05 "$ & & & & & & & & & & & & & & & & \\
\hline 10" & & & & & & & & & & & & & & & & \\
\hline $15 "$ & & & & & & & & & & & & & & & & \\
\hline $20 "$ & & & & & & & & & & & & & & & & \\
\hline $25 "$ & & & & & & & & & & & & & & & & \\
\hline $30 "$ & & & & & & & & & & & & & & & & \\
\hline $35^{\prime \prime}$ & & & & & & & & & & & & & & & & \\
\hline $40 "$ & & & & & & & & & & & & & & & & \\
\hline $45^{\prime \prime}$ & & & & & & & & & & & & & & & & \\
\hline $50 "$ & & & & & & & & & & & & & & & & \\
\hline $55 "$ & & & & & & & & & & & & & & & & \\
\hline 60" & & & & & & & & & & & & & & & & \\
\hline
\end{tabular}

Quadro 4- Modelo de um período de 15 minutos da planilha de coleta de dados.

Fonte: Gallo (2008, p. 36).

Conforme se observa no quadro 4 , os números da primeira linha correspondem aos minutos, enquanto os números da primeira coluna (esquerda) correspondem aos segundos (cada espaço corresponde a 5 segundos). A legenda de cada ação motora praticada pelo goleiro foi anotada no espaço correspondente (minutos/segundos aproximados) da ação. O quadro da planilha acima foi reproduzido por 6 vezes, sendo que cada um corresponde a 1/6 do jogo todo (períodos de 15 minutos cada). Abaixo as legendas das ações anotadas e utilizadas neste estudo:

$\mathbf{E}=$ posição de expectativa;

$\mathbf{D C B}=$ defesa central baixa;

DCM= defesa central média;

DCA= defesa central alta;

Conexões: revista da Faculdade de Educação Física da UNICAMP, Campinas, v. 8, n. 1, p. 16-37, jan./abr. 2010. 
DLDB= defesa lateral direita baixa;

DLDA = defesa lateral direita alta;

DLEB $=$ defesa lateral esquerda baixa;

DLEA= defesa lateral esquerda alta;

$\mathbf{C R}=$ cruzamento;

$\mathbf{A N}=$ antecipação;

$\mathbf{E N}=$ enfrentamento;

$\mathbf{R M}=$ reposição com as mãos;

$\mathbf{R P}=$ reposição com os pés.

\section{Apresentação dos resultados}

Os 12 jogos analisados totalizaram 455 ações do goleiro entre saltos/quedas/defesas, saídas do gol e reposições de bola. A média resultante deste estudo foi de 37,9 ações praticadas por jogo, que foram comparadas com dados encontrados na literatura, observando-se a posição do futebolista e se sua função está inserida nos padrões. No entanto, observa-se na figura 1 que não há uma quantidade uniforme de ações, para cada jogo, devido às circunstâncias que envolvem cada um deles.

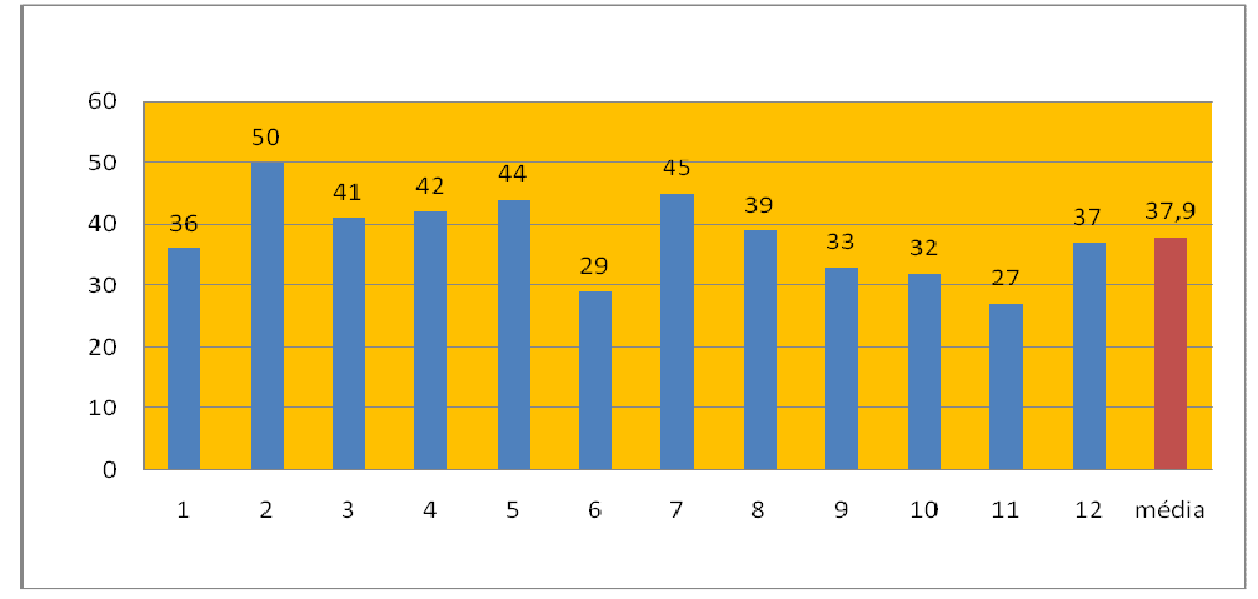

Figura 1- Total geral de ações do goleiro por jogo.

Os dados obtidos (total geral de ações nos 12 jogos), conforme planilha específica utilizada, que foram tabulados a cada 1/6 (15 minutos) do tempo total de jogo (90 minutos), estão apresentados no quadro 5.

No primeiro período (de 0 a15 minutos) dos 12 jogos, ocorreram 69 ações com média de 5,8 ações. No segundo período (de 15 a 30 minutos) foram 85 ações com média de 7,1. No terceiro período (de 30 a 45 minutos) ocorreram 70 ações com média de 5,8. No quarto período (de 45 a 60 minutos), que são os primeiros 15 minutos do $2^{\circ}$ tempo, realizaram-se 81 ações e a média foi de 6,8 . No quinto período (de 60 Conexões: revista da Faculdade de Educação Física da UNICAMP, Campinas, v. 8, n. 1, p. 16-37, jan./abr. 2010. 
a 75 minutos) ocorreram 66 ações com média de 5,5. E no sexto período (de 75 a 90 minutos) foram 84 ações com média de 7 ações. A média total de ações a cada 15 minutos de jogo foi de 6,3 ações.

Quanto à análise de cada jogo, em relação às ações específicas ocorridas a cada período de 15 minutos, apresentou diferenças significativas nas quantidades de ações entre um e outro período. Conforme se pode verificar no quadro 5 , há jogos com apenas 1 ação dentro de um período, como o caso dos jogos $\mathrm{n}^{\mathrm{o}} 6$ ( $4^{\circ}$ período) e $\mathrm{n}^{\mathrm{o}} 11$ ( $1^{\circ}$ período). Por outro lado, o jogo $\mathrm{n}^{\mathrm{o}} 7$ apresenta um período com 16 ações $\left(2^{\circ}\right.$ período). Outra situação é a que ocorreu no jogo $\mathrm{n}^{\circ} 5$, em que houve 30 ações nos três primeiros períodos (10 no primeiro, 11 no segundo e 9 no terceiro) com média de 10 ações, enquanto nos três últimos períodos foram 14 ações ( 5 no quarto, 5 no quinto e 4 no sexto) com média de 4,6 ações. A diferença entre os três primeiros períodos dos últimos três foi pouco mais que o dobro de ações. Estes resultados indicam que cada período é dependente das circunstâncias do jogo.

A média de ações de todos os jogos por período foi de 6,3 ações, o que representa 1 ação a cada 2 minutos e 40 segundos aproximadamente. No entanto, o jogo com menor média de ações por período é o de $n^{\circ} 11$ com média de 4,5 ações, que representa 1 ação a cada 3 minutos e 30 segundos. O jogo com maior média de ações é o n $^{\circ} 2$ com média de 8,3, que representa 1 ação a cada 1 minuto e 8 segundos.

\begin{tabular}{|c|c|c|c|c|c|c|c|c|}
\hline Jogo & \multicolumn{9}{|c|}{ Tempo de jogo } & Motal & Média \\
\hline & $0-15$ & $16-30$ & $31-45$ & $46-60$ & $61-75$ & $76-90$ & & \\
\hline 1 & 3 & 7 & 4 & 10 & 5 & 7 & 36 & 6,0 \\
\hline 2 & 6 & 8 & 5 & 11 & 11 & 9 & 50 & 8,3 \\
\hline 3 & 6 & 2 & 8 & 9 & 8 & 8 & 41 & 6,8 \\
\hline 4 & 8 & 5 & 7 & 3 & 10 & 9 & 42 & 7,0 \\
\hline 5 & 10 & 11 & 9 & 5 & 5 & 4 & 44 & 7,3 \\
\hline 6 & 10 & 7 & 2 & 1 & 2 & 7 & 29 & 4,8 \\
\hline 7 & 6 & 16 & 7 & 6 & 6 & 4 & 45 & 7,5 \\
\hline 8 & 4 & 6 & 9 & 6 & 5 & 9 & 39 & 6,5 \\
\hline 9 & 7 & 2 & 6 & 6 & 4 & 8 & 33 & 5,5 \\
\hline 10 & 4 & 6 & 5 & 9 & 3 & 5 & 32 & 5,3 \\
\hline 11 & 1 & 5 & 3 & 8 & 2 & 8 & 27 & 4,5 \\
\hline 12 & 4 & 10 & 5 & 7 & 5 & 6 & 37 & 6,2 \\
\hline Total & $\mathbf{6 9}$ & $\mathbf{8 5}$ & $\mathbf{7 0}$ & $\mathbf{8 1}$ & $\mathbf{6 6}$ & $\mathbf{8 4}$ & $\mathbf{4 5 5}$ & $\mathbf{7 5 , 8}$ \\
\hline Média & $\mathbf{5 , 8}$ & $\mathbf{7 , 1}$ & $\mathbf{5 , 8}$ & $\mathbf{6 , 8}$ & $\mathbf{5 , 5}$ & $\mathbf{7 , 0}$ & & $\mathbf{6 , 3}$ \\
\hline
\end{tabular}

Quadro 5- Total de ações do goleiro a cada 1/6 do jogo. 
$\overline{\text { Como se pode verificar há uma sucessão irregular no tempo em que as ações são praticadas durante cada }}$ jogo, caracterizando como aleatória a atividade do goleiro.

No quadro 6 é mostrado um exemplo de 1/6 da planilha de um jogo e os dados estão registrados no tempo em que ocorreram. As legendas das ações na planilha abaixo são: $\mathbf{E}=$ posição de expectativa, $\mathbf{C B}=$ defesa central baixa, $\mathbf{E B}=$ defesa do lado esquerdo baixo, $\mathbf{C R}=$ cruzamento, $\mathbf{R M}=$ reposição com as mãos, $\mathbf{R P}=$ reposição com os pés.

\begin{tabular}{|c|c|c|c|c|c|c|c|c|c|c|c|c|c|c|c|c|}
\hline & $\mathbf{0}^{\prime}$ & 1 ' & 2' & 3 & 4 & 5 & $6^{\prime}$ & 7 ' & 8 & 9' & $10^{\prime}$ & 11' & 12 & $13^{\prime}$ & $14^{\prime}$ & 15 \\
\hline $05^{\prime \prime}$ & & & & & & & & $\mathrm{E}$ & & & & & & & & \\
\hline $10 "$ & & & & & & & & & & & & & & & $\mathrm{E}$ & \\
\hline $15 "$ & & & & & & & & & & & & $\mathrm{RP}$ & & & & $\mathrm{E}$ \\
\hline $20 "$ & & & & & & & & $\mathrm{E}$ & $\mathrm{E}$ & & & & & & $\mathrm{E}$ & \\
\hline $25^{\prime \prime}$ & & & & & & & & & & & & & & & E & \\
\hline $30 "$ & & & & & & & & & & & & & & & & \\
\hline $35^{\prime \prime}$ & & & & & E & & & $\mathrm{E}$ & E & & & & & & & \\
\hline $40 "$ & & & & & $\begin{array}{c}\mathrm{E} / \mathrm{C} \\
\mathrm{B}\end{array}$ & & & & & & & & & $\begin{array}{c}\mathrm{E} / \mathrm{E} \\
\mathrm{B}\end{array}$ & & $\mathrm{E} / \mathrm{CR}$ \\
\hline $45^{\prime \prime}$ & & & & & RM & & & & & & & & & & & \\
\hline $50^{\prime \prime}$ & & & & & & & & & & & & & & & & $E$ \\
\hline $55^{\prime \prime}$ & & & & & & $\mathrm{E} / \mathrm{EB}$ & & & & & & & & & & \\
\hline $60 "$ & & & & & & & & & & & $\mathrm{E}$ & & & & & \\
\hline
\end{tabular}

\section{$E=16 ; C B=1 ; E B=2 ; C R=1 ; R M=1 ; R P=1$}

Quadro 6- Registro das ações do goleiro em 1/6 de jogo.

$\mathrm{Na}$ interpretação do quadro 6, o goleiro intervém, somente, aos 4 minutos e 40 segundos para praticar uma defesa central baixa e repõe a bola com as mãos. A seguir, aos 5 minutos e 55 segundos, faz uma defesa no seu lado esquerdo baixo. Aos 11 minutos e 15 segundos, depois de permanecer 5 minutos e 15 segundos aproximadamente sem participação ativa, repõe a bola com o pé. Faz outra defesa aos 13 minutos e 40 segundos pelo seu lado esquerdo baixo, e tem outra participação aos 15 minutos e 40 segundos na interceptação de um cruzamento, depois de 2 minutos sem ser empenhado. 
Foram 4 ações defensivas e 2 ofensivas, totalizando 6 , neste período. A média foi de 1 ação a cada 2 minutos e 50 segundos. Conforme se pode observar, foi uma seqüência irregular tanto das ações praticadas como no tempo em que ocorreram as mesmas.

Na figura 2 são apresentadas as porcentagens de ações em cada período. O período com maior número de ocorrências foi o segundo com $18,7 \%$ do total de ações, seguido pelo sexto (último do jogo) com 18,5\%. E o período com menos ações foi o quinto com $14,5 \%$. O que se pode notar neste estudo, pela porcentagem de ações em cada período, é que sempre ocorreu um período menos intenso e outro mais intenso. No entanto, cada período de cada um dos jogos, necessariamente, não se apresentou desta forma, conforme dados do quadro 5 .

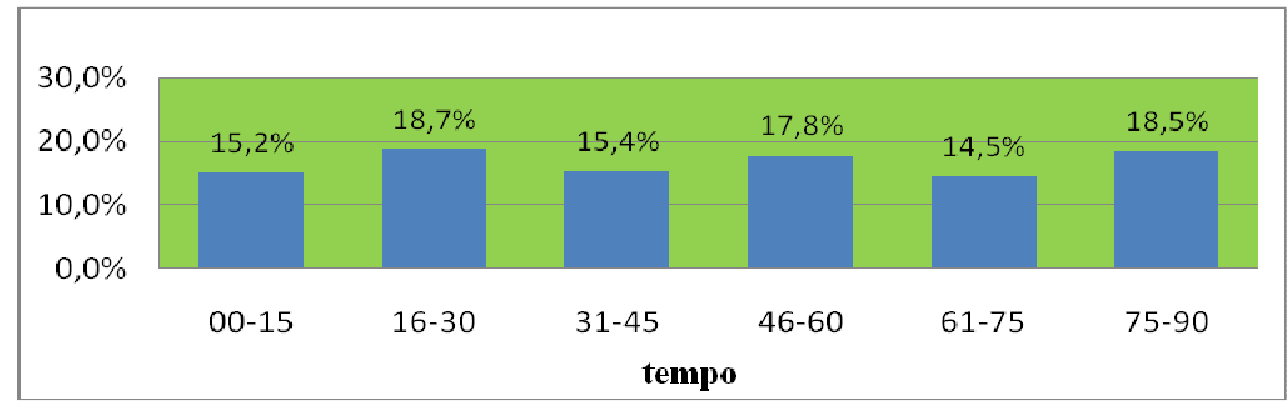

Figura 2- Porcentagem geral de ações do goleiro por período de jogo. 
$\overline{\text { A quantidade de ações específicas praticadas pelo goleiro durante os } 12 \text { jogos estão tabuladas em }}$ períodos de 15 minutos, conforme o quadro 7.

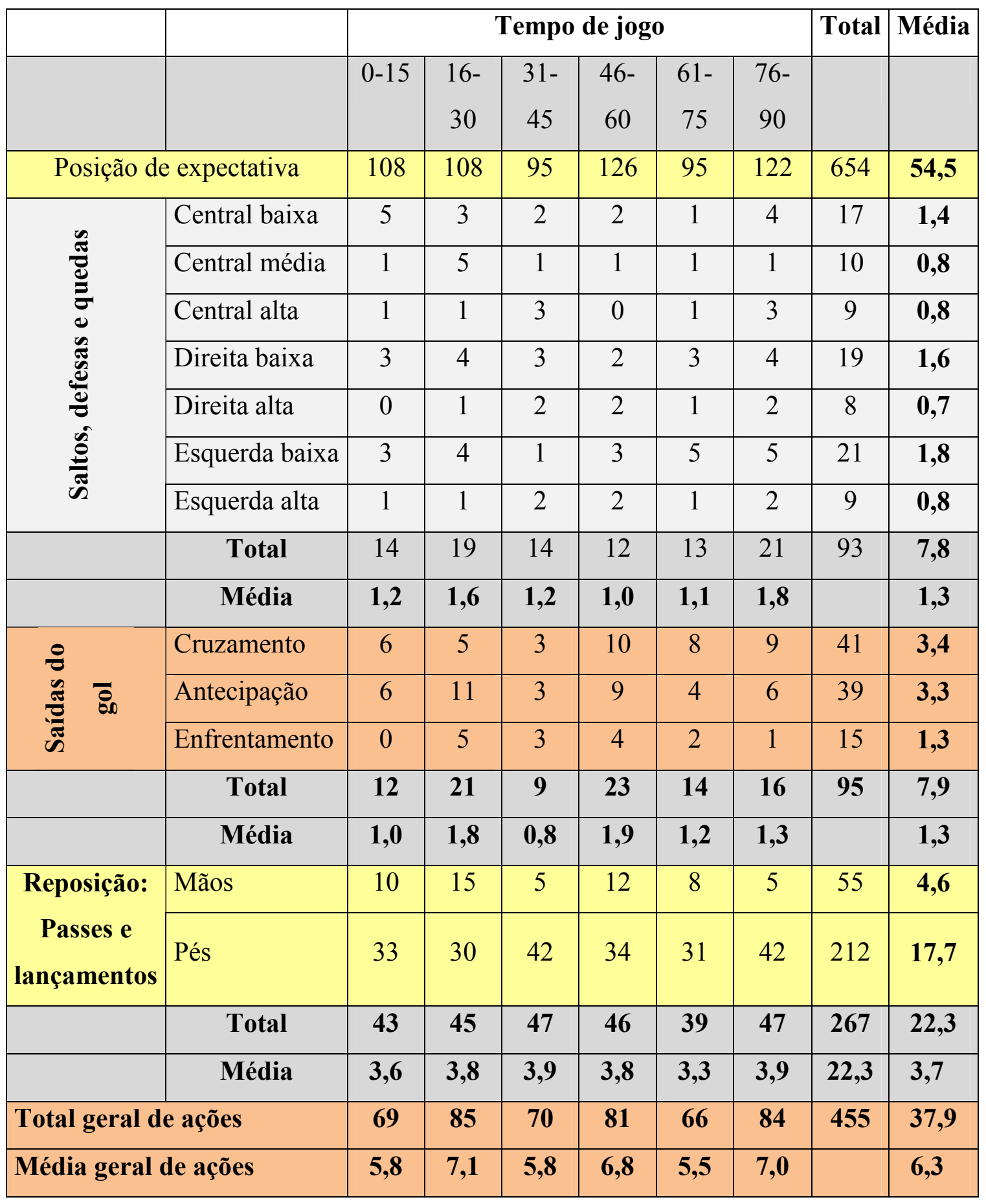

Quadro 7- Total geral de ações específicas do goleiro a cada 1/6 dos jogos. 
No primeiro período ocorreram 69 ações (média de 5,8) das quais 14 foram de saltos/quedas/defesas (média de 1,2), 12 saídas do gol (média de 1,0) e 43 reposições de bola ( média de 3,6). No segundo período foram 85 ações (média de 7,1) sendo 19 de saltos/quedas/defesas (média de 1,6), 21 saídas do gol (média de 1,8) e 45 reposições (média de 3,8). No terceiro período ocorreram 70 ações (média de 5,8) sendo 14 saltos/quedas/defesas (média de 1,2), 9 saídas do gol (média de 0,8) e 47 reposições de bola (média de 3,9). No quarto período foram 81 ações (média de 6,8) com 12 saltos/quedas/defesas (média de 1,0), 23 saídas do gol (média de 1,9) e 46 reposições (média de 3,8). O quinto período teve 66 ações (média de 5,5) que foram 13 saltos/quedas/defesas (média de 1,1), 14 saídas do gol (média de 1,2) e 39 reposições (média de 3,3). No sexto período foram 84 ações (média de 7,0) com 21 saltos/quedas/defesas (média de 1,8), 16 saídas do gol (média de 1,3) e 47 reposições de bola (média de 3,9). Verifica-se que o segundo período do jogo (média de 7,1 ações) e o último (média de 7,0 ações) são aqueles que apresentaram as maiores médias de ações do goleiro.

A média de cada período de 15 minutos (quadro 7) para as ações de saltos/quedas/defesas foi de 1,3. A média das saídas de gol foi, também, de 1,3 ações. A de reposição de bola foi de 3,7 ações por período. Em relação ao tempo total de cada jogo (90 minutos) a média para as ações específicas de saltos/quedas/defesas foi de 7,8 ações, enquanto para as ações de saídas de gol foi de 7,9 e de reposições de bola a média foi de 22,3 ações por jogo. Isto implica em 1 ação de salto/queda/defesa a cada 11 minutos e 53 segundos, aproximadamente, por jogo. Para as ações de saídas do gol foi de 1 ação a cada 11 minutos e 39 segundos. E para as reposições de bola foi 1 ação a cada 4 minutos de jogo.

Conforme dados apresentados no quadro 7, houveram 93 ações de saltos/quedas/defesas, 95 saídas do gol e 267 reposições de bola, que determina predominância nas ações ofensivas do goleiro sobre as defensivas. Em termos de porcentagem são $58,70 \%$ de reposições de bola contra $20,90 \%$ de saídas do gol e $20,40 \%$ de saltos/quedas/defesas. Portanto a diferença foi de $17,40 \%$ a mais para as ações ofensivas de reposição de bola (figura 3). 


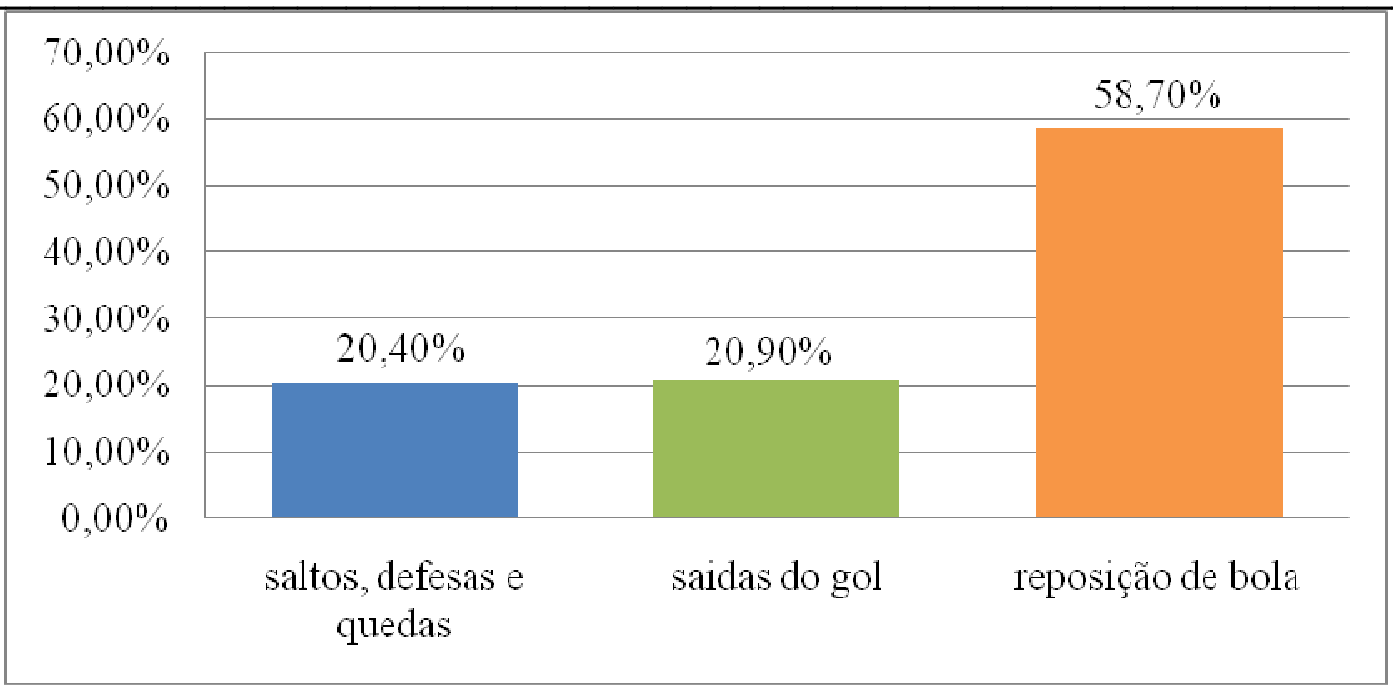

Figura 3- Porcentagens das ações do goleiro nos jogos.

Por intermédio destes dados, pode-se afirmar que as ações defensivas de saídas do gol (20,90\%) são tão importantes quanto às de saltos/quedas/defesas (20,40\%) que são decisivas, pois as proporções são praticamente as mesmas. Por outro lado, as reposições de bola $(58,70 \%)$ ocorrem em proporção muito mais elevada (mais que o dobro de cada uma das outras), sendo um indicativo de que, no futebol atual, este fundamento é relevante e deve ser considerado para efeito de treinamento. Considerando este fato, Kraemer e Häkkinen (2004) afirmam que o lançamento da bola com as mãos, por ser mais preciso, requer a necessidade de se elevar a força e a potência dos grupos musculares dos ombros, do peito e das costas para que o goleiro possa lançá-la o mais longe possível.

\section{CONCLUSÕES}

Com base nos resultados obtidos neste estudo, pode-se concluir que:

- Não há uma quantidade uniforme de ações, para cada jogo, devido às circunstâncias que envolvem cada um deles;

- A quantidade de ações a cada período de 15 minutos, é dependente das circunstâncias do jogo;

- Há sucessão irregular, tanto das ações praticadas como no tempo em que ocorreram, durante cada jogo;

- As ações ofensivas predominam sobre as defensivas, sendo 17,40\% a mais, em média, por jogo;

- De acordo com a média de porcentagem de ações em cada período de 15 minutos, sempre ocorreu um período menos intenso seguido por outro mais intenso;

- Os períodos com maiores participações do goleiro foram o segundo (média de 7,1 ações) e o último (média de 7,0 ações); 
- As principais atividades do goleiro no jogo, utilizadas de maneira decisiva, que se manifestam por intermédio das defesas e saídas do gol, são os eventos de força rápida (potência);

- A atividade de alta intensidade é de curtíssima duração e o tempo entre uma e outra é longo (1 ação a cada 2 minutos e 40 segundos aproximadamente, obtidos neste estudo) e suficiente para recuperação.

Verificou-se ainda que:

- A atividade do goleiro, no jogo de futebol, é caracterizada como aleatória;

- As ações ofensivas praticadas pelo goleiro (reposição de bola, início do contra-ataque) também ocupam papel relevante na sua atividade, não deixando de ser menos importante que as defensivas;

- O perfil caracterizado na atividade do goleiro implica mais na potência anaeróbica alática, que resulta em uma pequena depleção de ATP-CP, do que qualquer outra demanda no sistema de transporte de oxigênio.

O goleiro deve ser submetido a treinamento diferenciado e exclusivo, já que suas necessidades são diferentes dos futebolistas das outras posições. Os profissionais responsáveis pela preparação específica do goleiro devem, cada vez mais, analisá-lo nas condições específicas do jogo, para, além de atender suas necessidades, também contribuir com mais informações de pesquisas visando à evolução da área de preparação de goleiros.

\section{REFERÊNCIAS}

BALIKIAN, P.; et al. Consumo máximo de oxigênio e limiar anaeróbio de jogadores de futebol: comparação entre as diferentes posições. Revista Brasileira de Medicina do Esporte, Niterói: v. 8, n. 2, Mar./Apr. 2002.

BANGSBO, J. Energy demands in competitive soccer. Journal of Sports Sciences, v. 12, s5-s12, 1994. . Entrenamiento de la condición física en el fútbol. 4 ed, Badalona: Paidotribo, 2008.

BARBANTI, V. J. Treinamento físico: bases científicas. 2. ed, São Paulo: Balieiro, 2002.

CARLESSO, R. A. Manual de treinamento do goleiro. Rio de Janeiro: Palestra, 1981.

CSANÁDI, A. El fútbol. 4. ed. Barcelona: Planeta, 1987.

DOMINGUES, A. Goleiro 100 segredos. 20. ed, Curitiba: Verbo, 1997.

FLECK, S. J.; KRAEMER, W. J. Fundamentos do treinamento de força muscular. 2 ed. Porto Alegre: Artmed, 2002. 
FOSS, M. L.; KETEYIAN, S. J. Fox: bases fisiológicas do exercício e do esporte. 6 ed. Rio de Janeiro: Guanabara Koogan, 2000.

FREIRE, J. B. Pedagogia do futebol. Londrina : Midiograf, 1998.

FRISSELLI, A.; MANTOVANI, M. Futebol teoria e prática. São Paulo: Phorte, 1999.

GALLO, C. R. Análise das ações defensivas e ofensivas de um goleiro de futebol profissional e perfil metabólico da sua atividade. 2008. 48f. Monografia (Curso de Educação Física) - Universidade Paulista, Campinas, 2008.

GOMES, A. C. ; SOUZA, J. Futebol treinamento desportivo de alto rendimento. Porto Alegre: Artmed, 2008.

GOMES, P. S. C. et al. Physiological and morphological characteristics of the 1994 soccer world cup champions. Medicine and Science in Sports and Exercise. v. 27, n. 5 suppl., 1996.

KRAEMER, W. J.; HÄKKINEN, K. Treinamento de força para o esporte. Porto Alegre: Artmed, 2004. LA ROSA, A. F. Treinar para ganhar: a versão cubana do treinamento desportivo. São Paulo: Phorte, 2004.

LOPES, E. W. Caracterização da performance aeróbia e anaeróbia de goleiros de futebol através da análise de lactato: utilização de teste de corrida intermitente de "ida e volta", teste de Wingate e testes específicos de defesas. 2001. 107f. Dissertação (Mestrado) - Faculdade de Educação Física, Universidade Estadual Paulista, Rio Claro.

MAIER, S. Aprenda com o maior goleiro do mundo. Rio de Janeiro: Tecnoprint, 1981.

MAUGHAN, R.; GLESSON, M.; GREENHAFF, P. L. Bioquímica do exercício e treinamento. Barueri: Manole, 2000.

McARDLE, W. D.; KATCH, F. I.; KATCH, V. L. Fisiologia do exercício: energia, nutrição e desempenho humano. 5 ed. Rio de Janeiro: Guanabara Koogan, 2003.

POWERS, S. K.; HOWLEY, E. T. Fisiologia do exercício: teoria e aplicação ao condicionamento e ao desempenho. 3 ed. Barueri: Manole, 2000.

PRADO, W. L. et al., Perfil antropométrico e ingestão de macronutrientes em atletas profissionais brasileiros de futebol, de acordo com suas posições. Revista Brasileira de Medicina do Esporte, Niterói: v. 12, n. 2, Mar./Apr. 2006.

ROCHA FILHO, N. Caracterização dos jogadores de futebol de campo por posição tática através do estudo das variáveis antropométricas e de dinamometria isocinética.2000. 26f. (Monografia) - Faculdade de Educação Física, Universidade Estadual de Campinas, Campinas, 2000. 
SANT'ANNA, M.; ÁVILA, M. A. Preparação fisica do futebol: metodologia e estatística. Holambra: Cuca Fresca, 2006.

SOARES, J. M. C. O treino do futebolista: resistência, força, velocidade. Porto: v.1. Porto Editora, 2005. SELUIANOV, V. N.; SARSANIA, S. K. SARSANIA, K. S. Futebol: aspectos fisiológicos e metabólicos. Curitiba: Juruá, 2008.

TEIXEIRA, J. S.; BARRIONUEVO, M.; ISRAEL, A. Anais... I Simpósio para treinadores de goleiros. São Paulo, 2006.

VOSER, R. C.; GUIMARÃES, M. G. V.; RIBEIRO, E. R. Futebol: história, técnica e treino de goleiro. Porto Alegre: EDIPUCRS, 2006.

WEINECK, E. J. Futebol total: O treinamento fisico no futebol. Guarulhos: Phorte, 2000. 
Carlos Roberto Gallo

Universidade Paulista e Associação Atlética Ponte Preta

E-mail: carlosgallo56@yahoo.com

Carlos Aparecido Zamai

Universidade Paulista

cazamai@yahoo.com.br

\section{Laércio Vendite}

Universidade Estadual de Campinas / IMECC

\section{Cleyton Libardi}

Universidade Paulista

\section{Referência do artigo}

\section{ABNT}

GALLO C. R.; ZAMAI, C. A.; VENDITE L. LIBARDI C. Análise das Ações Defensivas e Ofensivas, e Perfil Metabólico da Atividade do Goleiro de Futebol Profissional. Conexões, v. 8, n. 1, p. 16-37, 2010.

\section{APA}

Gallo C. R., Zamai C. A. \& Vendite L. Libardi C. (2010). Análise das Ações Defensivas e Ofensivas, e Perfil Metabólico da Atividade do Goleiro de Futebol Profissional. Conexões, 8(1), 16-37.

\section{VANCOUVER}

Gallo CR, Zamai CA, Vendite L. Libardi C. Análise das Ações Defensivas e Ofensivas, e Perfil Metabólico da Atividade do Goleiro de Futebol Profissional. Conexões, 2010; 8(1): 16-37.

Recebido em: 04/01/2010

Aceito para publicação em fev. 2010 